\title{
Uma proposta didática para abordar o conceito de temperatura a partir de situações, à luz da teoria dos campos conceituais de Vergnaud
}

\author{
A didactical proposal to approach the temperature \\ concept based on situations, in the light of Vergnaud's \\ conceptual field theory
}

Edi Terezinha de Oliveira Grings

Concesa Caballero

Marco Antonio Moreira

\begin{abstract}
Resumo
Este trabalho apresenta uma proposta didática que utiliza situaçõesproblema para introduzir novos conceitos. A proposta foi aplicada numa turma de 32 alunos da Fundação Escola Técnica Liberato Salzano Vieira da Cunha, em Novo Hamburgo, RS, Brasil, onde se trabalhou o conceito de temperatura. A turma de alunos foi dividida em duplas para que fosse garantida a participação dos mesmos nas discussões a respeito das situações-problema. Durante a implementação da proposta as falas de uma dupla de alunas foram gravadas. Este trabalho faz uma análise das discussões das estudantes à luz da Teoria dos Campos Conceituais de Vergnaud e mostra que elas parecem acionar diversos esquemas e seus componentes durante o enfrentamento das situações-problema.
\end{abstract}

Palavras-chave: temperatura, proposta didática, campos conceituais.

\begin{abstract}
This paper presents an educational proposal that uses problem-situations to introduce new concepts. The proposal was applied in a group of 32 pupils from Liberato Salzano Vieira da Cunha Technical School, in Novo Hamburgo, RS, Brazil, where the concept of temperature was approached. The group of pupils was divided in pairs so that their participation was guaranteed in the discussions regarding the problem-situations. During the implementation of the proposal the discussions of a pair of pupils were recorded. This paper presents an analysis of these discussions in the light of Vergnaud's conceptual fields theory and shows that they seem to activate several schemes and his components when facing the problem-situations.
\end{abstract}

Keywords: temperature, educational proposal, conceptual fields. 


\section{Introdução}

Moreira (2004, p.28) visualizou na Teoria dos Campos Conceituais de Vergnaud um importante referencial teórico para o Ensino de Ciências. Assim, através do estudo desta teoria e de pesquisas realizadas anteriormente (Grings et al., 2006), tomou-se a decisão de utilizá-la como referencial teórico para uma proposta didática e uma pesquisa em sala de aula.

Este trabalho apresenta essa proposta didática de introdução dos conteúdos através da discussão de situações problemáticas por duplas de estudantes. Acredita-se que os conceitos adquirem sentido para os estudantes quando estes são expostos a situações-problema ${ }^{1}$. $O$ fato de os conteúdos serem introduzidos através de situações permite diagnosticar conhecimentos prévios dos estudantes que serão postos em evidência no momento da discussão. Acredita-se que, no decorrer das situações, é possível compreender as relações de filiações e rupturas entre os conhecimentos, uma vez que, enquanto os alunos resolvem as situações, têm oportunidade de desestabilizar seus conhecimentos, pois o desenvolvimento cognitivo acontece a partir do desenvolvimento de esquemas, mediante o enfrentamento de situações. Assim, o desenvolvimento cognitivo ocorre em diversas situações onde o estudante tem que ser ativo.

Diante do exposto, supõe-se que a resolução de situações, no início do desenvolvimento didático de novos conceitos, aciona os diversos fatores descritos desencadeando a construção de novos esquemas e portanto, o desenvolvimento cognitivo.

$\mathrm{Na}$ implementação da proposta, o confronto das duplas de estudantes com as situações foi mediado pelo professor, pois se admite que os alunos só têm condições de resolver algumas situações com a ajuda do professor e dos colegas. Ou seja, as situações devem ser propostas dentro do que Vygotsky chamou de zona de desenvolvimento proximal e sua solução deve ser mediada socialmente.

Este artigo apresenta a primeira parte de um trabalho maior que visa, através desta proposta didática, facilitar a alunos de ensino médio e técnico o domínio do Campo Conceitual da Termodinâmica. $\mathrm{O}$ objeto inicial desta investigação foi o estudo do conceito de temperatura.

${ }^{1}$ Segundo Vergnaud, são as situações que dão sentido aos conceitos, mas o sujeito precisa percebê-las como situações-problema. 


\section{Referencial teórico}

\section{A teoria dos campos conceituais de vergnaud}

A Teoria dos Campos Conceituais trata de desenvolvimento cognitivo (Vergnaud, 2003, p. 22). Campo Conceitual é um conjunto vasto e organizado de situações que necessita de um conjunto de esquemas, de conceitualizações e de representações simbólicas para enfrentá-las. Os conceitos só adquirem sentido em situações-problema com crescente complexidade. São as situações que constroem a referência do conceito (Grossi, 2001, p.16), isto é, são as situações que dão sentido aos conceitos. Um campo conceitual pode ser definido como um conjunto de situações, cuja apropriação exige uma variedade de conceitos, de procedimentos e de representações simbólicas. A teoria dos campos conceituais tem por finalidade propor uma estrutura que permita compreender as filiações e rupturas entre os conhecimentos (Vergnaud, 1993, p.1), tomando como premissa que a conceitualização é o núcleo do desenvolvimento cognitivo.

O conjunto de esquemas necessários à conceitualização é uma organização invariante do comportamento para uma classe de situações. Um esquema é um plano de ação, uma estratégia que abrange uma classe de situações, numa certa seqüência, para dar conta de uma tarefa de certa complexidade (Grossi, 2001, p.16).

Um esquema mental está constituído de quatro componentes: um ou vários objetivos gerais, declinando-se em objetivos específicos e antecipações; regras de ação, de tomada de informação e de controle; invariantes operatórios: conceitos-em-ação e teoremas-em-ação; e possibilidades de inferência (Vergnaud, 2004, p.104). Esses componentes dão conta de várias propriedades do esquema mental: a intencionalidade, o caráter gerador, o conhecimento do real, a adaptabilidade e o cálculo em situações.

Os esquemas são acionados de duas formas: quando os estudantes são expostos a classes de situações em que eles dispõem, no seu repertório de esquemas, em um dado momento de seu desenvolvimento conceitual e sob certas circunstâncias, das competências necessárias ao tratamento imediato da situação; e quando os estudantes expostos a situações não dispõem de todas as competências necessárias, o que os obriga a um tempo de reflexão e de exploração, a hesitações e tentativas frustradas, levando-os ao sucesso ou ao fracasso (Vergnaud, 1993, p.2). 
Para Caballero $(2003$, p. 147) a Teoria dos Campos Conceituais é importante para explicar os processos de aprendizagem de conceitos, uma vez que nela o problema central da cognição é a conceitualização. A potencialidade didática da Teoria dos Campos Conceituais está no fato de explorar vínculos entre a estrutura cognitiva humana e a estrutura de conceitos e, deste modo, descrever distintos níveis de conceitualização do conceito.

Vergnaud (1993, p.9) considera um conceito como constituído por três conjuntos: um conjunto de situações que dão sentido ao conceito; um conjunto de invariantes operatórios em que se baseia a operacionalidade dos esquemas, ou seja, os significados dos conceitos que estão amplamente implícitos; e um conjunto de representações simbólicas que permite representar um conceito, suas propriedades, as situações e os procedimentos de tratamento. O primeiro conjunto é o referente, o segundo o significado e o terceiro o significante do conceito.

\section{A teoria dos campos conceituais e a sala de aula}

O desenvolvimento cognitivo é uma conseqüência do desenvolvimento dos esquemas mentais. Assim, a atividade de sala de aula tem importância no desenvolvimento de esquemas e no acionamento de seus componentes (objetivos e antecipações, regras de ação, invariantes operatórios e inferências). Vergnaud (2004, p.36) busca em Vygotsky o papel do professor, no que diz respeito à zona do desenvolvimento proximal, que trata de um espaço de atividade conjunta do professor e dos alunos entre si, neste espaço, o professor auxilia o aluno a fazer alguma coisa que ele sozinho não poderá fazer, o professor atua como mediador.

Para Vergnaud (2004, p.37-38), o primeiro ato de mediação do professor é a escolha de situações para seus alunos. Consiste em propor situações que vão desestabilizá-lo cognitivamente, mas com a ajuda do professor e dos colegas, essas situações desestabilizadoras permitirão um avanço no desenvolvimento dos esquemas dos alunos. Assim, na verdade é necessário que o professor proponha situações que possibilitem o desenvolvimento de esquemas. É preciso trazer para a escola situações coletadas na vida cotidiana e, ao mesmo tempo, trazer o saber científico e os chamados saberes profissionais. Vergnaud $(2004,44)$ diz que não somente as situações são importantes para o ensino, mas também o acionamento de todos os componentes dos esquemas (invariantes operatórios, inferências, objetivos e antecipações e regras de ação). Assim, não é suficiente a escolha de uma situação, mas também é necessário que o estudante reconheça, nesta situação, algo que Ihe faça sentido. 
A avaliação no sentido de subsidiar a ação do professor com os alunos é outro fator importante para Vergnaud (2004, p.47). O autor alerta sobre a forma operatória do conhecimento (o fazer) e a forma predicativa (o explicar, o dizer) reforçando a importância de propor situações que permitam avaliar as competências do fazer e do dizer.

A escolha de situações, o auxílio oferecido ao aluno quando ele desenvolve situações e a avaliação no sentido de que o professor tenha condições de controlar o desenvolvimento das competências que ele objetiva são, para Vergnaud (2004, p.50), três atos importantes para o professor.

Ele (2004, p.38) afirma que o desenvolvimento didático consiste no interesse pelo conteúdo conceitual dos conhecimentos. Assim, ele dá grande importância aos processos de conceitualização, uma vez que abarcam todos os registros da atividade.

Outro fator importante no ensino é o sistema de representações que o professor usa. Normalmente, são usadas muitas palavras e representações simbólicas, então é necessária uma epistemologia dos sistemas de representação para cada domínio de conteúdo (Vergnaud, 2004, p. 40). A pesquisa em sala de aula é importante, pois abarca a riqueza e a diversidade das atividades tanto da parte dos alunos quanto do professor. É necessário que os professores pensem em equipes de pesquisa no ensino para que possam dar conta da dimensão dos problemas didáticos (idem, 2004, p.41).

\section{Materiais e métodos}

\section{Proposta didática}

No delineamento desta investigação foi sorteada uma turma de terceira série do Curso Técnico de Eletrotécnica da Fundação Liberato, localizada em Novo Hamburgo, Brasil. A metodologia foi operacionalizada através do enfrentamento e discussão de situações-problema pelos alunos distribuídos em dezesseis duplas, para a introdução de novos conteúdos e conceitos. A escolha pela distribuição da turma em duplas busca garantir a participação de todos os alunos nas discussões e facilita a mediação do professor.

Durante a operacionalização da proposta didática uma dupla de alunas, que se propôs espontaneamente, teve suas discussões gravadas para posterior análise. Assim, este trabalho apresenta as discussões destas alunas analisadas à luz da Teoria dos Campos Conceituais de Vergnaud. A exposição dos alunos a estas situações-problema visou introduzir o conceito de temperatura. Esta foi a primeira aplicação da proposta didática que terá continuidade com a 
introdução de outros conceitos importantes do Campo Conceitual da Termodinâmica. As situações-problema discutidas são apresentadas no apêndice.

A proposta didática foi aplicada na turma 2311 (32 alunos), estudantes do turno da manhã, cujas aulas foram distribuídas conforme tabela 1.

Tabela 1: Caracterização das aulas durante o desenvolvimento do

conceito temperatura.

\begin{tabular}{|l|l|l|l|l|}
\hline Data & Tempo & Aula & Gravação de uma dupla & Atividade \\
\hline $14 / 06$ & $50 \mathrm{~min}$ & 1 & Ariane e Solange & Situações sobre temperatura \\
\hline $15 / 06$ & $50 \mathrm{~min}$ & 2 & Ariane e Solange $-20 \mathrm{~min}$. & $\begin{array}{l}\text { Situações sobre temperatura (término) } \\
\text { Discussão de um texto sobre } \\
\text { temperatura. Observação de } \\
\text { termômetros. }\end{array}$ \\
\hline $21 / 06$ & $50 \mathrm{~min}$ & 3 & & $\begin{array}{l}\text { Discussão do texto sobre temperatura } \\
\text { (escalas termométricas) }\end{array}$ \\
\hline $21 / 06$ & $50 \mathrm{~min}$ & 4 & & $\begin{array}{l}\text { Simulação computacional sobre } \\
\text { movimento de átomos e moléculas } \\
\text { (temperatura) e escalas termométricas }\end{array}$ \\
\hline $22 / 06$ & $50 \mathrm{~min}$ & 5 & & $\begin{array}{l}\text { Atividade prática - Calibração de um } \\
\text { termômetro a álcool e um sensor do tipo } \\
\text { NTC. }\end{array}$ \\
\hline $26 / 06$ & $50 \mathrm{~min}$ & 6 & & \begin{tabular}{l} 
Resolução de problemas \\
\hline
\end{tabular}
\end{tabular}

\section{Resultados e discussão}

Para fazer a análise interpretativa das gravações obtidas, quando a dupla de estudantes foi submetida à confrontação com as situações a respeito de temperatura, utilizaram-se categorias para diagnosticar como os estudantes acionam seus esquemas durante a exposição a situações que os desestabilizem e permitam que eles dêem sentido aos novos conceitos.

Como já foi dito, Vergnaud (1993, p. 2) distingue duas classes de situações: uma em que ele ou ela já dispõe de esquema que lhe permita enfrentar tal situação; e a outra em que o estudante ainda não dispõe de um esquema e, neste caso, experimenta vários esquemas que entram em competição ou podem ser agregados para resolver a situação; neste sentido 
definiram-se duas categorias na interpretação das falas das estudantes, conforme mostra a Tabela 2.

Tabela 2: Definição de categorias para a análise da discussão das alunas

- a partir do acionamento dos esquemas.

\begin{tabular}{|l|l|}
\hline PR & $\begin{array}{l}\text { Nesta categoria busca-se interpretar na fala dos estudantes, se os esquemas que } \\
\text { estão utilizando são esquemas prontos (EPR) a serem acionados. Neste caso, o } \\
\text { comportamento é amplamente automatizado e acionado por um só esquema que dá } \\
\text { conta da situação proposta. }\end{array}$ \\
\hline CO & $\begin{array}{l}\text { Nesta categoria incluíram-se esquemas que estão sendo construídos (ECO) } \\
\text { durante a ação. Assim, os estudantes, ao enfrentar em as situações fazem uso de vários } \\
\text { esquemas, que vão sendo combinados e recombinados até a obtenção do esquema } \\
\text { adequado. }\end{array}$ \\
\hline
\end{tabular}

$\mathrm{Na}$ análise interpretativa visou-se evidenciar quais os componentes dos esquemas que são postos em ação mediante o enfrentamento das situações. Quando o estudante enfrenta uma situação de uma classe ele aciona um conjunto de ações organizadas que permite gerar comportamentos distintos característicos, porém organizados, para cada situação a enfrentar nessa classe. Vergnaud (1993, p.19) explica que a organização invariante do comportamento frente a uma classe de situações é possível porque o esquema abrange quatro componentes: os invariantes operatórios, antecipações, regras de ação e inferências. Assim, definiram-se quatro categorias postas em evidência durante o desenvolvimento das situações (tabela 3). Grande parte da resolução de uma situação não é explicitada, por isso definiram-se categorias apenas a partir do que foi posto em evidência.

Tabela 3: Definição de categorias para a análise da discussão das alunas

- a partir do acionamento de componentes dos esquemas.

\begin{tabular}{|l|l|}
\hline OP & $\begin{array}{r}\text { Invariantes operatórios são os conceitos-em-ação e teoremas-em-ação que } \\
\text { indicam o reconhecimento pelo estudante dos componentes da situação, são conceitos e } \\
\text { teoremas acionados no ato do desenvolvimento da situação. }\end{array}$ \\
\hline NT & $\begin{array}{r}\text { Antecipações são os efeitos esperados e eventuais etapas intermediárias que } \\
\text { são postas em evidência mediante a situação a tratar, são os objetivos a alcançar. }\end{array}$ \\
\hline EA & $\begin{array}{c}\text { Regras de ação do tipo "se...então..." são regras que determinam a seqüencia } \\
\text { das ações do aluno. }\end{array}$ \\
\hline
\end{tabular}




\begin{tabular}{|l|r|}
\hline $\mathbf{N F}$ & Inferências são operações intelectuais que permitem determinar as regras e as \\
antecipações a partir das informações e invariantes operatórios que o estudante dispõe.
\end{tabular}

Além de tentar diagnosticar os tipos de esquemas e seus componentes acionados durante o desenvolvimento das situações, é importante constatar em que momento da situação são necessárias filiações e rupturas. Quando Vergnaud $(2003$, p.58) fala de filiações e rupturas ele explica que quando se aprende alguma coisa nova, algumas vezes temos de nos apoiar em conhecimentos anteriores e outras vezes esses conhecimentos anteriores podem tornar-se obstáculo para o novo conhecimento. Entende-se como filiações o apoio dos novos conhecimentos em conhecimentos anteriores e como rupturas quando é necessário romper com o conhecimento anterior para aquisição do novo conhecimento. A tabela 4 apresenta as categorias que visam reconhecer na conversa dos estudantes a necessidade de filiações e rupturas.

Tabela 4: Definição de categorias para a análise da discussão das alunas

- a partir do diagnóstico de filiações e rupturas.

\begin{tabular}{|l|l|}
\hline IL & $\begin{array}{l}\text { Na categoria filiações, identifica-se, no discurso dos estudantes, a necessidade de } \\
\text { buscar em conhecimentos anteriores apoio para o desenvolvimento do novo } \\
\text { conhecimento; }\end{array}$ \\
\hline UP & $\begin{array}{l}\text { Na categoria rupturas, identifica-se na fala dos estudantes a necessidade de } \\
\text { romper com algum conhecimento anterior, uma vez que este conhecimento pode } \\
\text { tornar-se obstáculo à nova conceitualização. }\end{array}$ \\
\hline
\end{tabular}

Na aula do dia 13/06/2007, $50 \mathrm{~min}$, e no dia 14/06/2007, 25 min (1período e meio), os alunos foram submetidos ao enfrentamento de seis situações a respeito de temperatura. Foram feitos recortes da discussão de uma dupla de estudantes, enquanto desenvolvia tais situações, e foram analisados de acordo com as categorias explicadas anteriormente. Esses recortes estão apresentados nas tabelas 5 (situação 1), 6 (situação 2), 7 (situação 3), 8 (situação 4), 9 (situação 5) e 10 (situação 6). Nessas tabelas a professora está indicada como P, as alunas estão identificadas como A e B e as falas grifadas correspondem àquelas que na percepção dos autores poderiam dar pistas sobre a utilização de conhecimentos anteriores (FIL), rupturas com conhecimentos prévios (RUP), uso de invariantes operatórios (IOP) e regras de ação (REA), ou ainda, possibilidades de inferência (INF) e antecipações (ANT). 
Tabela 5: Análise da discussão da situação um.

\begin{tabular}{|c|c|}
\hline NT & $\begin{array}{l}\text { A aluna A faz a leitura da situação: } \\
\text { 1) Uma pessoa encontra-se com febre. } \\
\text { a) Como é possível perceber a febre desta pessoa? Através do aumento da } \\
\text { temperatura. } \\
\text { B: Não, mas depois, como tu vais ver o aumento da temperatura? Como tu vais } \\
\text { ver que aumentou a temperatura? } \\
\text { A:Tu vais perceber a febre. }\end{array}$ \\
\hline EA & $\begin{array}{l}\text { B: Não, através do termômetro. Vai ter o aumento. Já que está com febre, vai ter } \\
\text { aumento de temperatura. }\end{array}$ \\
\hline CO & $\begin{array}{l}\text { A: Mas será que é pelo instrumento? Ou é para dizer, pelo aquecimento? } \\
\text { Porque aqui é para diagnosticar o estado febril e não febril. Aqui é para dizer a } \\
\text { temperatura que é febril e não febril. } \\
\text { B: Ah! Tá. } \\
\text { A: Eu acho. } \\
\text { B: Certo. A temperatura do corpo, eu acho que é } 35^{\circ} \text {. } \\
\text { A: } 36^{\circ} \text {, acima de } 36^{\circ} \text { é febre. }\end{array}$ \\
\hline OP & $\begin{array}{l}\text { A: Professora, aqui na um é para falar através das alterações do corpo ou do } \\
\text { instrumento? } \\
\text { P: Pode explicar das duas formas. Com a alteração observada no corpo, qual é a } \\
\text { alteração observada no instrumento? } \\
\text { A: A temperatura do corpo normal é } 35 \text { ou } 36 \text {. } \\
\text { P: } 36,5^{\circ} \text {. } \\
\text { A: Acima de } 36,5^{\circ} \text { é febre. } \\
\text { P: É. }\end{array}$ \\
\hline NT & $\begin{array}{l}\text { A: Uma pessoa encontrando-se com febre como é possível perceber a febre } \\
\text { desta pessoa? É possível perceber a febre desta pessoa através de um aparelho. Através } \\
\text { do termômetro. É possível perceber a febre através do termômetro. }\end{array}$ \\
\hline NF & B: Quando marcar. \\
\hline
\end{tabular}




\begin{tabular}{|l|l|}
\hline B: Espera aí, talvez ele tenha... \\
A: $36,5^{\circ} \mathrm{C}$. Como tu diagnosticarias o estado febril e o não febril? O estado febril é \\
quando a temperatura do corpo é maior do que $36,5^{\circ}$. E o estado não febril é inferior ou \\
igual a $36,5^{\circ}$.
\end{tabular}

Através das respostas à primeira situação (tabela 5) pode-se pensar que as estudantes acionam um conjunto de esquemas (ECO), que vão compondo e recompondo para resolver a situação. Pode-se, também, pensar que as respostas das estudantes, sugerem o funcionamento dos componentes do esquema. Quando a aluna B questiona sobre como se vai observar o aumento de temperatura, ela parece estar fazendo referência ao objetivo que se quer alcançar (ANT), ou seja, como saber o estado febril ou não-febril de uma pessoa.

Ao comentar "já que tem febre vai ter um aumento de temperatura", aluna B provavelmente aciona uma regra de ação (REA), argumentando que o aumento de temperatura é uma conseqüência da febre. Quando a estudante A relaciona a temperatura do corpo com um valor numérico, supõe-se que ela está invocando um invariante operatório (IOP), que está implícito, mas que evidencia uma relação entre a temperatura do corpo e um valor numérico. A aluna $B$, quando fala sobre marcar uma determinada temperatura, através das antecipações, de regras de ação e de invariantes operatórios, infere (INF) sobre o estado febril ou não febril de uma pessoa.

Tabela 6: Análise da discussão da situação dois.

\begin{tabular}{|c|c|}
\hline NT & $\begin{array}{l}\text { A aluna A lê a situação 2: } \\
\text { 2)A figura abaixo mostra duas panelas com uma determinada substância. A } \\
\text { segunda mostra uma maior energia cinética média do movimento de agitação de seus } \\
\text { átomos e moléculas. Como você relacionaria a energia cinética média do movimento de } \\
\text { agitação de seus átomos e moléculas com a sensação térmica das panelas? Por quê? } \\
\text { A: Tá, a figura abaixo mostra duas panelas com uma determinada substância. } \\
\text { B: As duas são iguais, a segunda mostra uma maior energia cinética média do } \\
\text { movimento de agitação dos seus átomos e moléculas. Como você relacionaria a energia } \\
\text { cinética média do movimento de agitação de seus átomos e moléculas com a sensação } \\
\text { térmica das panelas? Por quê? }\end{array}$ \\
\hline EA & $\begin{array}{l}\text { B: Ah! Esta está com uma temperatura maior que esta. } \\
\text { A: Por causa do movimento das moléculas. }\end{array}$ \\
\hline & B: Porque elas são a mesma, \\
\hline
\end{tabular}




\begin{tabular}{|l|l|}
\hline PR & $\begin{array}{l}\text { movimentam mais. } \\
\text { A: Então é com o aumento da energia cinética. A segunda panela tem um } \\
\text { movimento maior, porque a temperatura inicial é maior que a primeira. Como você } \\
\text { relacionaria a energia cinética média do movimento de agitação de seus átomos e } \\
\text { moléculas com a sensação térmica das panelas? Bom, a sensação térmica da segunda é } \\
\text { maior que ... } \\
\text { B: a da primeira. } \\
\text { A: A sensação térmica da segunda é maior que a da primeira. } \\
\text { B: Segunda panela. } \\
\text { A: Segunda panela é maior que a sensação térmica da primeira. } \\
\text { B: Da primeira panela. } \\
\text { A: da primeira panela. } \\
\text { B: panela. } \\
\text { A: Por que? } \\
\text { B: Por que? } \\
\text { A: Porque com o aumento do movimento das moléculas, há um aumento de } \\
\text { temperatura. }\end{array}$ \\
\hline
\end{tabular}

Inicialmente, as alunas buscam os objetivos a alcançar (ANT) (tabela 6), através do diálogo elas procuram se inteirar desses objetivos. Em seguida, em conjunto elas parecem acionar uma regra de ação (REA), "se está com uma temperatura maior, há um movimento maior das moléculas". Esta regra permite imaginar a presença de um invariante operatório (IOP) que relaciona "maior sensação térmica com maior agitação das moléculas e aumento de temperatura". Nesta situação, também é possível supor uma concorrência entre esquemas (EPR), uma vez que as alunas constroem e reconstroem sua resposta, dando evidência do acionamento de mais de um esquema.

Tabela 7: Análise da discussão da situação três.

\begin{tabular}{|l|l|}
\hline IL & A aluna A lê a situação. \\
& 3)Vamos supor que na situação 2, a segunda panela tivesse o dobro do volume, \\
& com o mesmo comportamento dos átomos e moléculas. Você observaria diferença na \\
\hline
\end{tabular}




\begin{tabular}{|c|c|}
\hline & $\begin{array}{l}\text { mperatura? O dobro do volume, se tivesse mais. } \\
\text { B: Acho que sim, porque tem aquela fórmula, da quantidade. }\end{array}$ \\
\hline OP & $\begin{array}{l}\text { A: Mas é a quantidade de calor, o volume, aumentaria a massa, aumentaria a } \\
\text { quantidade de calor, mas aquele } \Delta U \text { é a diferença de outra coisa, não é a temperatura. } \\
\text { B: A temperatura então está relacionada ao movimento das moléculas. } \\
\text { A: Essa aqui tipo água, se colocar fogo na água vai demorar menos para ferver. }\end{array}$ \\
\hline NF & $\begin{array}{l}\text { B: Porque, na situação } 2 \text {, se a segunda panela tivesse o dobro do volume com o } \\
\text { mesmo comportamento dos átomos, aumenta. } \\
\text { A: É, mas é o mesmo comportamento dos átomos e moléculas. } \\
\text { B: observaríamos diferença na temperatura. } \\
\text { A: Não, pois o movimento dos átomos continua igual. }\end{array}$ \\
\hline OP & $\begin{array}{l}\text { B: É porque o movimento seria proporcional ao, seria igual ao que tivesse } \\
\text { menos, porque eles se comportam igual. } \\
\text { A: das moléculas. } \\
\text { B: Não, o movimento dos átomos e moléculas. } \\
\text { A: Dos átomos e moléculas. } \\
\text { B: Não teria alteração de comportamento. } \\
\text { A: então vamos colocar assim, porque o movimento dos átomos e moléculas... } \\
\text { eu tinha pensado a palavra, daí tu falaste... os átomos e moléculas. Os átomos e } \\
\text { moléculas, eles têm o mesmo comportamento, né? Os átomos e moléculas continuam } \\
\text { movimentando. } \\
\text { B: Apesar de o volume ser o dobro, eles têm o mesmo comportamento. }\end{array}$ \\
\hline CO & $\begin{array}{l}\text { A: Não, porque os movimentos dos átomos e moléculas têm a mesma } \\
\text { intensidade após o aumento do volume. Têm o mesmo comportamento. } \\
\text { B: Têm a mesma intensidade. } \\
\text { A: Tem a mesma intensidade, o comportamento dos átomos e moléculas. } \\
\text { B: É que eu tenho receio de colocar palavras diferentes. } \\
\text { A: Têm o mesmo comportamento, mesmo após o aumento de volume, mesmo } \\
\text { após o aumento do volume da panela. O volume da panela. }\end{array}$ \\
\hline
\end{tabular}


Ao tentar responder à situação três (tabela 7), a estudante B faz referência a uma fórmula, um conhecimento anterior (FIL) para resolver a situação. Mas a estudante A argumenta que aquele $\Delta U$ não é diferença de temperatura, sendo necessário aí uma ruptura (RUP) com o conhecimento anterior. Em seguida, há evidência do acionamento de um invariante operatório (IOP), conceito-em-ação quando a aluna relaciona a temperatura ao movimento de moléculas. $\mathrm{E}$ finalmente ambas parecem fazer uso da inferência (INF), quando concluem que não há diferença de temperatura, pois o comportamento dos átomos e moléculas é o mesmo. Quando a aluna B diz que apesar de o volume ser o dobro, os átomos e moléculas têm o mesmo comportamento, não está explícito, mas se pode deduzir a existência do teorema-em-ação (IOP): "o aumento do volume não interfere no movimento dos átomos e moléculas". E, finalmente, pela fala das estudantes, acredita-se que novamente vários esquemas (ECO) entram em ação sem que nenhum dê conta sozinho da situação o que levaria à acomodação cognitiva através da construção (ECO) de novo(s) esquema(s) para temperatura e energia cinética de átomos e moléculas.

Tabela 8: Análise da discussão da situação quatro.

\begin{tabular}{|c|c|}
\hline NF & $\begin{array}{l}\text { A aluna A lê a situação: } \\
\text { 4)A água de uma chaleira a temperatura ambiente apresenta determinada } \\
\text { energia cinética média de movimento de seus átomos e moléculas. Quando a chaleira } \\
\text { é colocada sobre uma chama, há um aumento da energia cinética média de seus } \\
\text { átomos e moléculas. Por quê? A chaleira será submetida a um aumento de } \\
\text { temperatura. } \\
\text { B: Há uma troca de energia com a energia do fogão mais a energia da panela, } \\
\text { causando um aumento de temperatura. }\end{array}$ \\
\hline EA & $\begin{array}{l}\text { A: A água da chaleira que tinha a temperatura ambiente e se equilibra a } \\
\text { temperatura submetida. } \\
\text { B: Não, porque ela não vai se equilibrar, ela vai chegar no máximo até } 100^{\circ} \text { e } \\
\text { vai ferver. } \\
\qquad \text { A: A chaleira será submetida a um aumento de temperatura, então a } \\
\text { temperatura ambiente da água da chaleira aumentará com o tempo até chegar a } \\
100^{\circ} \text {. }\end{array}$ \\
\hline $\mathbf{N} 1$ & $\begin{array}{l}\text { A: Por que vai aumentar a temperatura? } \\
\text { B: Porque vai haver uma maior movimentação dos átomos e moléculas. } \\
\text { A: Sim, mas é isto que ela está perguntando, por que vai haver uma }\end{array}$ \\
\hline
\end{tabular}




\begin{tabular}{|c|c|}
\hline NF/ECO & movimentação de átomos e moléculas. \\
\hline I & $\begin{array}{r}\text { A: A água da chaleira será submetida a um aumento de temperatura que } \\
\text { impulsionará o movimento dos átomos. } \\
\text { B: Impulsionará o movimento dos átomos e moléculas, porque A: Porque a } \\
\text { água da chaleira será submetida a um aumento de temperatura, que aumentará o } \\
\text { movimento dos átomos e moléculas e, conseqüentemente, a energia cinética. } \\
\text { B: Está. } \\
\text { A: Conseqüentemente, a energia cinética. }\end{array}$ \\
\hline
\end{tabular}

Inicialmente, as alunas parecem fazer uma inferência (INF) (tabela 8) quando, a partir do enunciado, concluem que há um aumento de temperatura. Então, aparentemente, as alunas acionam uma regra de ação (REA), se a chaleira for submetida a um aumento de temperatura, então necessariamente a água chegará a $100^{\circ} \mathrm{C}$. Observa-se, também, um retorno ao objetivo da situação anterior, quando a aluna A volta a se perguntar por que vai haver uma movimentação dos átomos e moléculas. Podemos supor, ainda, que as estudantes fazem novamente uso da inferência (INF) quando, a partir das informações apresentadas, supõem um aumento do movimento dos átomos e moléculas e da energia cinética como conseqüência do aumento de temperatura. Nesta situação, também se pode pensar que vários esquemas são acionados para a resolução da situação (ECO).

Tabela 9: Análise da discussão da situação cinco

\begin{tabular}{|c|c|}
\hline UP & $\begin{array}{l}\text { 5) Vamos supor uma situação em que a energia cinética média dos átomos e } \\
\text { moléculas que constituem um corpo seja praticamente nula, ou seja, os átomos e } \\
\text { moléculas estão praticamente em repouso. Poder-se-ia relacionar esta situação com } \\
\text { uma temperatura? Poder-se-ia fazer leituras de temperaturas inferiores a esta? Por quê? } \\
\qquad \text { B: Acho que sim, sim poderia, eles estão a } 0^{\circ} \text {, eles estão congelados. } \\
\text { A: Poderia se relacionar com alguma temperatura, sim é que a gente não sabe } \\
\text { qual é a situação, porque ela não explicou, quando está a } 0^{\circ} \text {, se realmente estão parados } \\
\text { ou não. }\end{array}$ \\
\hline EA & $\begin{array}{l}\text { B: Inferior, ela está dizendo que é baixa. } \\
\text { A: Mas está perguntando. }\end{array}$ \\
\hline
\end{tabular}




\begin{tabular}{|c|c|}
\hline & $\begin{array}{l}\text { B: Sim eu sei, praticamente nula. Quando for nula a energia cinética. } \\
\text { A: A energia cinética, bem mas não mede a temperatura. } \\
\text { B: Não, mas quando a temperatura é baixa, eles não se movimentam. } \\
\text { B: Poder-se-ia relacionar esta situação com alguma temperatura. Relaciona-se } \\
\text { m uma temperatura muito baixa, quase chegando a } 0^{\circ} \text {. }\end{array}$ \\
\hline NT & $\begin{array}{l}\text { A: Poder-se-ia fazer leituras de temperaturas inferiores a esta? Sim, porque, } \\
\text { tem que ver o porquê da primeira. Sim, porque apesar de ela estar praticamente nula, } \\
\text { tem uma certa temperatura. Ela está pedindo para relacionar ... movimento com a } \\
\text { temperatura. }\end{array}$ \\
\hline CO & $\begin{array}{l}\text { B: Pode, né? Tem que dizer por que, por que ela é alta ou ela é baixa. } \\
\text { A: Porque ela é baixa. Poder-se-ia relacionar esta situação com alguma } \\
\text { temperatura? } \\
\text { B: Não lembra do que ocorreu ontem? Quando a água está fervendo, elas } \\
\text { estavam muito movimentadas. } \\
\text { A: Está, eu sei, mas... } \\
\text { B: Tu achas que no gelo elas se movimentam? Provavelmente a temperatura } \\
\text { não vai ser alta. } \\
\text { A: Relaciona-se com uma temperatura muito baixa. Deve ser zero ou não. } \\
\text { B: Mas, só pelo movimento de moléculas dá para dizer. } \\
\text { A: Mas, tu não sabes se é a zero ou abaixo de zero. } \\
\text { B: Pois é. } \\
\text { A: Então só responde muito baixa. } \\
\text { B: Praticamente nula, ela vai estar nula abaixo de zero. } \\
\text { A: Bom, daí eu não sei. } \\
\text { B: A gente pode responder, apenas, que ela se relaciona a uma temperatura } \\
\text { muito baixa. }\end{array}$ \\
\hline NF & $\begin{array}{l}\text { A: Poder-se ia fazer leituras de temperaturas inferiores a esta? } \\
\text { B: Professora, aqui praticamente nula, é como se ela estivesse parada. } \\
\text { P: É aquela situação de mínima energia possível. }\end{array}$ \\
\hline
\end{tabular}




\begin{tabular}{|l|l|}
\hline & A: Mínima, então não pode ter temperaturas inferiores. \\
P: Como é a situação mínima possível, não poderia ter temperaturas inferiores a \\
esta. \\
A: Até porque elas já estão paradas, elas já estão paradas, pois já estão na \\
situação... \\
B: mínima que pode chegar.
\end{tabular}

Na situação cinco (tabela 9), as alunas relacionam a situação de mínima energia com a temperatura de $0^{\circ} \mathrm{C}$, que é uma temperatura conhecida para elas. Neste caso, são necessárias uma ruptura (RUP) e a compreensão de que há uma escala de temperatura específica que relaciona o movimento dos átomos e moléculas com a temperatura e que esta escala não é a escala Celsius. As alunas parecem estar construindo regras de ação (REA), quando dizem que, se a temperatura é baixa, os átomos não se movimentam. Elas, a todo o momento, voltam aos objetivos a serem alcançados, ou seja, às antecipações (ANT), pois retornam ao questionamento feito por meio da situação. Quando as estudantes chegam ao impasse, elas solicitam a mediação da professora, pois, como sabem que existem temperaturas negativas e estão relacionando a situação de energia mínima à temperatura de $0^{\circ} \mathrm{C}$, elas se desestruturam. Após a intervenção da professora, as estudantes inferem (INF), que não podem existir temperaturas inferiores a $0 \mathrm{~K}$. Durante o desenvolvimento desta situação, podemos supor que houve o acionamento de vários esquemas (ECO) e a possível construção de outro para dar conta de situações envolvendo temperaturas muito baixas, na escala Kelvin.

Tabela 10: Análise da discussão da situação seis

\begin{tabular}{|c|c|}
\hline EA & $\begin{array}{l}\text { 6)Um corpo A, a uma temperatura de } 60^{\circ} \mathrm{C} \text {, é colocado em contato com um } \\
\text { corpo B, cuja temperatura é } 20^{\circ} \mathrm{C} \text {, sendo ambos isolados de influências externas. } \\
\text { a)O que vai acontecer com a temperatura do corpo A e com a temperatura do } \\
\text { corpo B? } \\
\text { A: A temperatura do corpo A irá diminuir e a do B aumentar. } \\
\text { b)O que acontece com os átomos e moléculas de } A \text { e de B? Por quê? } \\
\text { A: Os átomos e moléculas de A irão diminuir a movimentação, e as moléculas } \\
\text { de B irão aumentar a movimentação para então um corpo entrar em equilíbrio com a } \\
\text { temperatura do outro. }\end{array}$ \\
\hline
\end{tabular}




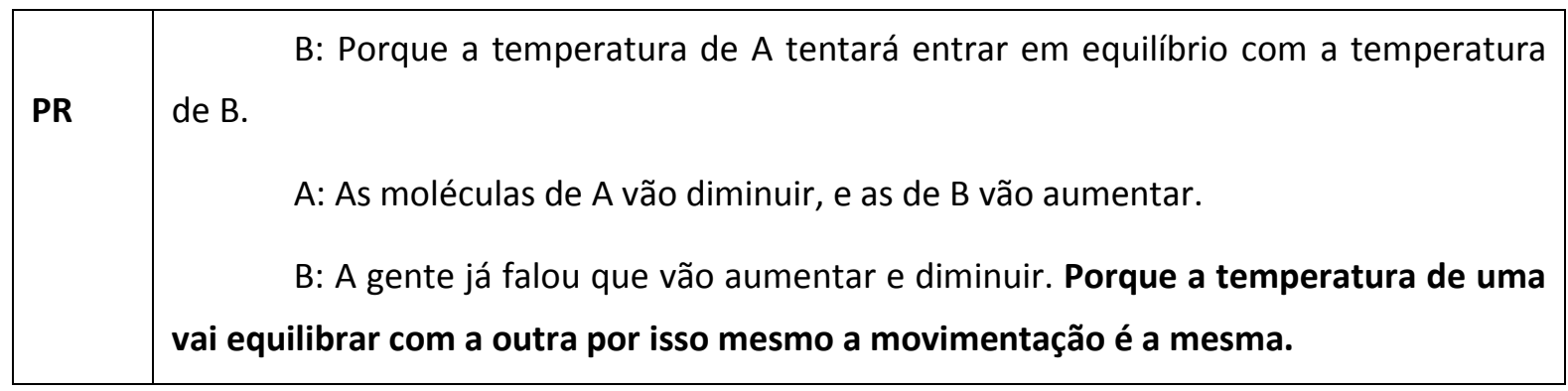

Na situação seis (tabela 10), parece que as estudantes fazem uso de um esquema que dá conta da situação (EPR). Parece também que utilizam uma regra de ação (REA), pois como conseqüência do aumento e da diminuição do movimento dos átomos e moléculas, as alunas chegam à conclusão que as temperaturas dos corpos atingem um equilíbrio, ou seja, "há equilíbrio térmico quando a movimentação das moléculas é a mesma”. Este seria um teoremaem-ação.

\section{Conclusão}

Esta proposta didática introduz os conteúdos aos estudantes através de situações a resolver, uma vez que para Vergnaud (2003, p.36) "o primeiro ato de mediação possível do professor é a escolha de situações para seus alunos". O autor (op. cit., p.53) defende a necessidade de desestabilizar o aluno e, ao mesmo tempo, de conduzi-lo de maneira a focalizar a atenção nos aspectos necessários. Nestas aulas, introduziu-se o conceito de temperatura, a partir de situações propostas com o objetivo de dar sentido ao conceito de temperatura. Assim, mediante cada uma das situações, os estudantes viram-se confrontados com o fato de a temperatura estar relacionada ao movimento de átomos de moléculas. As situações devem também desestabilizar cognitivamente os estudantes sem levá-los a abandonar a tarefa. A situação quatro mostrou desestabilizar as estudantes, uma vez que elas tentaram relacionar a situação de energia mínima à temperatura de $0^{\circ} \mathrm{C}$, ficando a dúvida se poderiam existir temperaturas inferiores a situação em que a energia é mínima, uma vez que desconheciam ainda a escala Kelvin de temperatura. Uma vez que a situação é percebida como problemática o conceito que dá conta dela ganha sentido para o aluno. Quer dizer, o conceito de temperatura Kelvin adquire sentido para o estudante mediante situações-problema. Mas conceitualização requer muitas situações em diferentes níveis de complexidade. 
Para Vergnaud (op.cit., p.39), "a revolução didática consiste em propor situações que possibilitem o desenvolvimento de esquemas". Neste trabalho, cremos que as estudantes puseram em concorrência diversos esquemas para solucionar as situações um, dois, três, quatro e cinco. Já na situação seis, houve evidência da utilização de apenas um esquema, uma vez que as estudantes, de imediato, solucionaram a situação. Assim, durante o desenvolvimento das situações parece que as estudantes foram relacionando o conceito de temperatura ao movimento de átomos e das moléculas chegando à questão seis com um esquema aparentemente construído. Assim, parece-nos que durante a exposição das estudantes a situações-problema, houve evidência do desenvolvimento de esquemas. Poder-se-ia também dizer que as situações facilitaram a conceitualização dando sentido ao conceito de temperatura. Para Vergnaud, a conceitualização é o núcleo do desenvolvimento cognitivo. Para Piaget a acomodação, ou seja, a construção ou modificação de esquemas de assimilação é o centro desse desenvolvimento. Mas para Vergnaud, os conceitos, como foi dito na fundamentação teórica deste trabalho, são definidos por um conjunto de situações (o referente) que lhe dão sentido, um conjunto de invariantes operatórios (o significado) e um conjunto de representações simbólicas (o significante). Destes conjuntos, o dos invariantes operatórios é um dos ingredientes dos esquemas de Piaget. Há, portanto, coerência entre as duas posturas teóricas, de modo que podemos falar, hipoteticamente, tanto em construção de esquemas para dominar situações envolvendo o conceito de temperatura como na construção do próprio conceito de temperatura. É preciso reiterar, no entanto, que são processos lentos e complexos, nos quais as situaçõesproblema são essenciais e não devem ser confundidas com os clássicos "problemas" de Física que não passam de exercícios de aplicação de fórmulas e geralmente levam à aprendizagem mecânica.

\section{Referências}

Caballero, M.C. La progresividad del aprendizaje significativo de conceptos. Textos de Apoio do Programa Internacional de Doutorado em Ensino de Ciências da Universidade de Burgos/UFRGS, v. 5, pp.137-154, 2003.

Grings, E.T.O., Caballero, C. e Moreira, M.A. Possíveis indicadores de invariantes operatórios apresentados por estudantes em conceitos da termodinâmica. Revista Brasileira de Ensino de Física, 28(4), pp. 1-9, dez. 2006. 
Grossi, E.P. Esquemas de pensamento, campos conceituais, teoremas em ação: um espaço de problemas do pós-construtivismo. Seminário Internacional sobre Didática da matemática, Porto Alegre, 2001.

Moreira, M.A. A teoria dos campos conceituais de Vergnaud, o ensino de ciências e a pesquisa nesta área. In: A Teoria dos Campos Conceituais de Vergnaud, o Ensino de Ciências e a Investigação nesta Área. Porto Alegre: Instituto de Física da UFRGS, 2004.

Vergnaud, G. Lev Vygotski: pedagogo e pensador do nosso tempo. Porto Alegre: GEEMPA, 2004. Vergnaud, G. Teoria dos campos conceituais. In: Nasser, L. (Ed.) Anais do 1 Seminário Internacional de Educação Matemática do Rio de Janeiro, pp. 1-26, 1993.

Vergnaud, G. A gênese dos campos conceituais. In: Grossi, Esther Pillar. Por que ainda há quem não aprende? 2.ed. Petrópolis: Editora Vozes, 2003.

Vergnaud, G. e Grossi, E.P. Esquemas operatórios de pensamento: uma conversa com Gérard Vernaud. In: Grossi, E.P. Ensinando que todos aprendem: fórum social pela aprendizagem. Porto Alegre: GEEMPA, 2005.

Edi Terezinha de Oliveira Grings - Fundação Escola Técnica Liberato Salzano Vieira da Cunha, Novo Hamburgo, RS.

editog@terracom.br

Concesa Caballero - Departamento de Física, Faculdade de Ciências UBU, Burgos, Espanha. concesa@ubu.es

Marco Antonio Moreira - Instituto de Física da UFRGS.

moreira@if.ufrgs.br 


\section{Apêndice - situações sobre temperatura}

Discuta em dupla e responda as seguintes situações:

1) Uma pessoa encontra-se com febre.

a) Como é possível perceber a febre desta pessoa?

b) Como você diagnosticaria o estado febril e o não-febril?

2) A figura abaixo mostra duas panelas com uma determinada substância. A segunda mostra uma maior energia cinética média do movimento de agitação dos átomos e das moléculas da substância. Como você relacionaria a energia cinética média do movimento de agitação de átomos e moléculas da substância com a sensação térmica das panelas? Por quê?

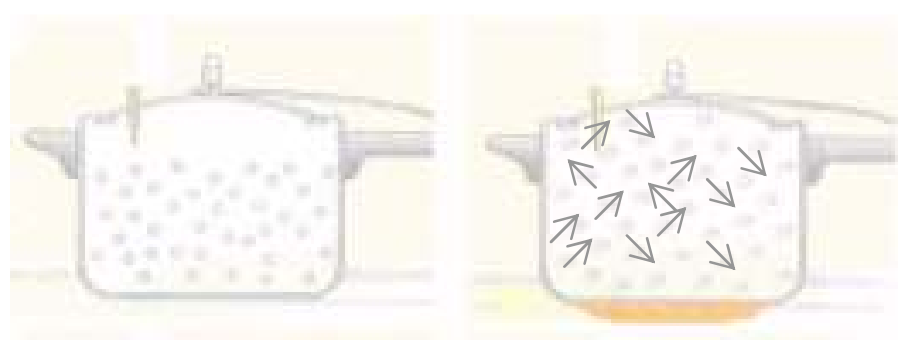

(Máximo e Alvarenga, 1997)

3) Vamos supor que na situação 2, a segunda panela tivesse o dobro do volume, com o mesmo comportamento dos átomos e das moléculas da substância. Você observaria diferença na temperatura? Explique.

4) A água de uma chaleira à temperatura ambiente apresenta determinada energia cinética média de movimento de seus átomos e moléculas. Quando a chaleira é colocada sobre uma chama, há um aumento da energia cinética média dos átomos e moléculas da água. Por quê? 
5) Vamos supor uma situação em que a energia cinética média dos átomos e moléculas que constituem um corpo seja praticamente nula, ou seja, os átomos e as moléculas estão praticamente em repouso. Poder-se-ia relacionar esta situação com uma temperatura? Poder-se-ia fazer leituras de temperaturas inferiores a esta? Por quê?

6) Um corpo $\mathrm{A}$, a uma temperatura de $60^{\circ} \mathrm{C}$, é colocado em contato com um corpo $\mathrm{B}$, cuja temperatura é $20^{\circ} \mathrm{C}$, sendo ambos isolados de influências externas.

a) O que vai acontecer com a temperatura do corpo $A$ ? $E$ com a temperatura do corpo $B$ ?

b) O que acontece com os átomos e moléculas de $\mathrm{A}$ e de B? Por quê? 